\title{
Pemanfaatan Google Earth Engine dalam Pemetaan Pemetaan Potensi Karbon Provinsi Kalimantan Timur
}

\author{
Erina Hertianti \\ Pengolahan Hasil Hutan, Politeknik \\ Pertanian Negeri Samarinda, \\ Samarinda, 75131 \\ erinanugroho1970@gmail.com
}

\author{
Dawamul Arifin \\ Teknologi Geomatika, Politeknik \\ Pertanian Negeri Samarinda, \\ Samarinda, 75131 \\ dawamularifin@politanisamarinda.a \\ c.id
}

\author{
Romansah Wumu \\ Teknologi Geomatika, Politeknik \\ Pertanian Negeri Samarinda, \\ Samarinda, 75131 \\ romansah@politanisamarinda.ac.id.c \\ om
}

\begin{abstract}
Abstrak - Perubahan iklim merupakan permasalahan serius yang dihadapi dunia internasional. Salah satu factor yang mempengaruhi perubahan iklim adalah pelepasan $\mathrm{CO} 2$ yang berasal dari vegetasi/ hutan. Hal tersebut menjadikan pengelolaan dan pemeliharaan vegetasi harus dilakukan dengan baik untuk mencegah pelepasan CO2. Provinsi Kalimantan Timur merupakan salah satu provinsi dengan tutupan vegetasi yang luas. Untuk mengetahui potensi karbon yang dimiliki oleh Provinsi Kalimantan Timur dapat dilakukan perhitungan melalui perhitungan luasan jenis tutupan lahan dan kemudian dikalikan dengan factor pengali dari potensi karbon yang terdapat pada jenis tutupan lahan tersebut. Perhitungan luasan dalam rangka perhitungan potensi karbon dapat dilakukan secara lebih mudah dengan menggunakan Google Earth Engine (GEE) yang mampu melakukan processing data secara serentak/ sekaligus. Pengolahan data juga dapat dilakukan dengan menambahkan parameter-parameter dalam pengolahan image. Pengolahan citra sentinel-2 dalam penentuan tutupan lahan menghasilkan 3 kelas tutupan lahan yakni badan air (384.754,752 ha), pemukiman (463.396,001 ha) dan vegetasi $(11.873 .800,520$ ha). Dari luasan tersebut diperoleh potensi karbon yang ada di Provinsi Kalimantan Timur adalah sebesar 761.267.197,15 ton.
\end{abstract}

Kata Kunci- Potensi Karbon, Sentinel-2, Tutupan Lahan, GEE.

\section{PENDAhUluan}

Perubahan komposisi atmosfer mengakibatkan perubahan iklim. Perubahan komposisi atmosfer disebabkan oleh peningkatan konsentrasi gas rumah kaca (GRK). Pelepasan CO2 yang berasal dari biomassa dalam hutan gambut dan permukaan bumi menyumbang $20 \%$ dari peningkatan GRK. Hal ini bisa terjadi sebagai akibat dari deforestasi dan degradasi hutan serta lahan gambut yang meletakkan Indonesia sebagai salah satu emitter terbesar ketiga di dunia.

Penanganan perubahan iklim dapat dilakukan dengan penentuan kebijakan, akan tetapi untuk menentukan kebijakan yang tepat maka diperlukan informasi terkait seberapa besar emisi gas rumah kaca yang terjadi di Indonesia. Informasi terkait besarnya tingkat emisi dan sebarannya ini dapat digunakan untuk menetapkan kebijakan dalam pembangunan sehingga sehingga pada satu sisi dapat memenuhi kebutuhan hidup manusia dan pada sisi lainnya dapat seoptimal mungkin mengurangi dampak perubahan iklim.

Di Indonesia, mitigasi perubahan iklim dilakukan dengan menjaga kondisi hutan. Indonesia berkerjasama dengan World Bank melalui sebuah program pendanaan untuk menjaga stok karbon. Program tersebut tersebut bernama Carbon Fund. Indonesia menerima pendanaan hibah dari Forest Carbon Partnership Facility (FCPF) yang merupakan lembaga kemitraan global yang focus pada upaya konservasi karbon, pengelolaan hutan lestari, pengurangan emisi melalui pencegahan deforestasi dan degradasi hutan, serta peningkatan cadangan karbon di negara berkembang. Hibah FCPF yang diberikan kepada Indonesia bertujuan untuk penguatan kapasitas Indonesia dalam merancang sebuah strategi nasional yang menyeluruh dalam pengendalian emisi dengan menjaga stok karbon yang ada.

Terdapat sebuah skema yang memungkinkan negara berkembang untuk menjaga hutannya dan mendapatkan insentif dari hasil penyerapan karbon atau berkurangnya emisi akibat kerusakan hutan, skema tersebut adalah program Reducing Emission from Deforestation and Forest Degradation (REDD). Program REDD mewajibkan negara yang mendapatkan dana untuk menjaga hutannya dari deforestasi dan degradasi agar dapat menyerap karbon (carbon sink) dan menahan karbon (carbon stock) yang dihasilkan dari pola produksi dan konsumsi di tempat lain di dunia. Insentif dana akan diberikan berdasarkan jumlah banyaknya karbon yang dapat ditahan oleh hutan di suatu daerah, sehingga diperlukan perhitungan untuk mengetahui stok karbon tersebut.

Kalimantan timur terpilih sebagai wilayah Pilot Project di Indonesia untuk menjalankan program REDD dari FCPF. Data tutupan lahan yang menjadi dasar perhitungan nilai stok karbon yang ada disuatu wilayah belum secara valid dimiliki oleh setiap Kab/Kota di 
Kalimantan Timur. Untuk itu perlu dilakukan perhitungan stok karbon melalui metode penginderaan jauh berbasis data tutupan lahan untuk dapat memperoleh nilai estimasi stok karbon dan emisi karbon yang ada.

Teknik penginderaan jauh digunakan sebagai salah satu metode estimasi karena lebih unggul dalam segi biaya dan waktu pengukuran, serta dapat diterapkan untuk area hutan yang luas dan memiliki banyak variasi bentukan fisik. Dengan metode penginderaan jauh dapat ditentukan stok karbon dari suatu luasan hutan dengan berbagai macam variasi sehingga hasil estimasi stok karbon dapat semakin akurat. Selain itu, dengan data nilai estimasi stok karbon tersebut maka dapat ditentukan langkah-langkah untuk turut serta berperan dalam pengelolaan lingkungan khususnya dalam pengendalian emisi karbon baik secara nasional bahkan global/ internasional.

\section{STUDI PUSTAKA}

\section{A. Hutan}

Sebuah ekosistem yang saling berketergantungan dan terdiri dari berbagai macam tumbuhan disebut hutan. Undang-undang no. 41 tahun 1999 menjelaskan bahwa yang dimaksud dengan hutan adalah sumberdaya alam hayati yang berada pada satu hamparan luas wilayah dalam satu kesatuan ekosistem dan didominasi jenis pepohonan yang terikat dengan kondisi lingkunganya (Dephut, 1999). Hutan yang berada disuatu wilayah memiliki ciri khusus yang membedakannya dengan hutan yang berada diwilayah lain (Rahman, 1992). Hutan memiliki fungsi untuk menjaga tutupan awan, membantu proses pengubahan air menjadi uap, memantulkan sinar matahari keluar atmosfer, meningkatkan kelembaban atmosfer yang mampu menurunkan suhu udara.

Hutan berhubungan secara langsung dengan perubahan iklim. Menurut Sularso (2011), sebuah kondisi dimana terjadi perubahan atas fisik atmosfer bumi seperti distribusi curah hujan dan temperature serta memiliki dampak luas terhadap kehidupan manusia disebut dengan perubahan iklim. Salah satu factor utama dalam perubahan iklim adalah gas rumah kaca (GRK). GRK yang didominasi oleh $\mathrm{CO} 2, \mathrm{CH} 4$ dan $\mathrm{N} 2 \neg \mathrm{O}$ menjadi factor utama dalam perubahan iklim. Atifitas manusia dalam melakukan perubahan penggunaan lahan dan penggunaan bahan bakar fosil untuk aktivitas industry, transportasi dan pembangkit energi merupakan penyebab peningkatan $\mathrm{CO} 2$ di atmosfer (Lusiana et al, 2005). Perubahan penggunaan lahan ini juga terjadi pada areal hutan dimana manusia melakukan penebangan, perambahan, konversi lahan hutan, kebakaran hutan dan aktivitas lainnya sehingga secara tidak langsung menyebabkan peningkatan emisi gas rumah kaca (Daud, 2014). Pengelolaan hutan, pengendalian deforestasi, penerapan silvikultur yang baik, perbaikan bahan organic tanah dan pencegahan degradasi lahan gambut serta penanaman tanaman berkayu merupakan usaha yang dapat dilakukan untuk mempertahankan dan meningkatkan cadangan karbon (Bakri, 2009).

\section{B. Karbon}

Biomassa vegetasi adalah berat bahan vegetasi hidup yang tersusun dari bagian bawah dan atas permukaan tanah dalam waktu tertentu. Biomassa terbentuk dari senyawa utama berupa karbohidrat yang terdiri dari unsur oksigen, hydrogen dan karbondioksida (Hairiah dan Rahayu, 2007). Biomassa hutan tersusun dari karbon sebanyak $47 \%$ sehingga dapat digunakan untuk menduga potensi serapan karbon (SNI 7724, 2011).

Karbon merupakan salah satu unsur baik dalam bentuk cair, gas ataupun padat yang ada didalam batang pohon, perut bumi dan atmosfer (udara). Karbon yang berada diatas permukaan tanah terdiri dari biomassa tumbuhan bawah (tumbuhan menjalar, rumput, dan semak belukar), biomassa pohon, serasah dan nekromasa. Karbon merupakan unsur yang terdapat pada biomassa dengan prosentase jumlah sebanyak $45-50 \%$ dari berat kering biomassa (Whitmore, 1985). Proses sekuestrasi (Csequestration) merupakan proses penimbunan karbon (C) dalam tubuh tumbuhan hidup. Banyakanya $\mathrm{CO} 2 \mathrm{di}$ atmosfer yang diserap oleh tanaman dapat digambarkan dengan mengukur jumlah $\mathrm{C}$ yang disimpan dalam tubuh tanaman hidup (biomassa) pada suatu lahan. Sedangkan pengukuran $\mathrm{C}$ yang masih tersimpan dalam bagian tumbuhan yang telah mati (nekromasa) secara tidak langsung menggambarkan CO yang tidak dilepaskan ke udara lewat pembakaran (Hairiah dan Rahayu, 2007). Cadangan karbon untuk tipe tutupan lahan skala nasional dapat dilihat pada tabel 1. ((Tosiani, 2015):

Tabel 1. Cadangan karbon per hektar untuk jenis tutupan lahan skala nasional

\begin{tabular}{|c|l|c|l|}
\hline No & \multicolumn{1}{|c|}{$\begin{array}{c}\text { Kelas Penutupan } \\
\text { Lahan }\end{array}$} & $\begin{array}{c}\text { Kandungan } \\
\text { Karbon } \\
\text { (C ton/ ha) }\end{array}$ & \multicolumn{1}{|c|}{$\begin{array}{c}\text { Sumber } \\
\text { Data }\end{array}$} \\
\hline 1 & Belukar Rawa & 30 & $\begin{array}{l}\text { Juknis PER } \\
\text { RAD GRK, } \\
2013\end{array}$ \\
\hline 2 & Bandara/Pelabuhan & 0 & $\begin{array}{l}\text { Juknis PER } \\
\text { RAD GRK, } \\
2013\end{array}$ \\
\hline 3 & $\begin{array}{l}\text { Hutan Lahan Kering } \\
\text { Primer }\end{array}$ & 132,99 & $\begin{array}{l}\text { NFI (1996- } \\
2013), 2014\end{array}$ \\
\hline 4 & $\begin{array}{l}\text { Hutan Lahan Kering } \\
\text { Sekunder }\end{array}$ & 98,84 & $\begin{array}{l}\text { NFI (1996- } \\
2013), 2014\end{array}$ \\
\hline 5 & $\begin{array}{l}\text { Hutan Mangrove } \\
\text { Primer }\end{array}$ & 188,3 & $\begin{array}{l}\text { Litbanghut, } \\
2014\end{array}$ \\
\hline 6 & $\begin{array}{l}\text { Hutan Mangrove } \\
\text { Sekunder }\end{array}$ & 94,07 & $\begin{array}{l}\text { Litbanghut, } \\
2014\end{array}$ \\
\hline 7 & Hutan Rawa Primer & 96,35 & $\begin{array}{l}\text { NFI (1996- } \\
2013), 2014\end{array}$ \\
\hline 8 & $\begin{array}{l}\text { Hutan } \\
\text { Sekunder }\end{array}$ & $\begin{array}{l}\text { NFI (1996- } \\
2013), 2014\end{array}$ \\
\hline 9 & Hutan Tanaman & 98,38 & $\begin{array}{l}\text { Litbanghut, } \\
2014\end{array}$ \\
\hline 10 & Lahan Terbuka & $\begin{array}{l}\text { Juknis PER } \\
\text { RAD GRK, } \\
2013\end{array}$ \\
\hline 11 & Perkebunan & Juknis PER \\
\hline
\end{tabular}




\begin{tabular}{|c|c|c|c|}
\hline & & & $\begin{array}{l}\text { RAD GRK, } \\
2013\end{array}$ \\
\hline 12 & Permukiman & 4 & $\begin{array}{l}\text { Juknis PER } \\
\text { RAD GRK, } \\
2013\end{array}$ \\
\hline 13 & $\begin{array}{l}\text { Pertanian Lahan } \\
\text { Kering }\end{array}$ & 10 & $\begin{array}{l}\text { Juknis PER } \\
\text { RAD GRK, } \\
2013\end{array}$ \\
\hline 14 & $\begin{array}{l}\text { Pertanian Lahan } \\
\text { Kering Campur }\end{array}$ & 30 & $\begin{array}{l}\text { Juknis PER } \\
\text { RAD GRK, } \\
2013\end{array}$ \\
\hline 15 & Pertambangan & 0 & $\begin{array}{l}\text { Juknis PER } \\
\text { RAD GRK, } \\
2013\end{array}$ \\
\hline 16 & Savanna & 4 & $\begin{array}{l}\text { Juknis PER } \\
\text { RAD GRK, } \\
2013\end{array}$ \\
\hline 17 & Sawah & 2 & $\begin{array}{l}\text { Juknis PER } \\
\text { RAD GRK, } \\
2013\end{array}$ \\
\hline 18 & Semak/Belukar & 30 & $\begin{array}{l}\text { Juknis PER } \\
\text { RAD GRK, } \\
2013\end{array}$ \\
\hline 19 & Tambak & 0 & $\begin{array}{l}\text { Juknis PER } \\
\text { RAD GRK, } \\
2013\end{array}$ \\
\hline 20 & Transmigrasi & 10 & $\begin{array}{l}\text { Juknis PER } \\
\text { RAD GRK, } \\
2013\end{array}$ \\
\hline 21 & Tubuh Air & 0 & $\begin{array}{l}\text { Juknis PER } \\
\text { RAD GRK, } \\
2013\end{array}$ \\
\hline 22 & Rawa & 0 & $\begin{array}{l}\text { Juknis PER } \\
\text { RAD GRK, } \\
2013\end{array}$ \\
\hline
\end{tabular}

\section{Tutupan Lahan}

Tutupan lahan (Land Cover) adalah kondisi fisik suatu ruang di permukaan bumi (EUROSTAT, 2001). Fariz et al. (2014) juga mengungkapkan bahwa kenampakan di permukaan bumi seperti bangunan, danau dan vegetasi dapat didefinisikan sebagai penutup lahan. Menurut dokumen SNI tahun 2014 tentang klasifikasi penutup lahan, penutup lahan juga didefinisikan sebagai tutupan biofisik permukaan bumi yang dapat diamati sebagai hasil tindakan manusia terhadap kondisi dari hamparan wilayah tertentu untuk melakukan kegiatan perubahan, produksi atau perawatan terhadap wilayah tersebut. Penutup lahan dibedakan kedalam dua kelas besar yakni daerah bervegetasi dan daerah tidak bervegetasi.

\section{Satelit Sentinel-2}

Sentinel-2 adalah satelit penginderaan jauh dengan sensor pasif dan memiliki 13-band spectral yaitu band 1, 9, dan 10 memiliki ketelitian spasial $60 \mathrm{~m}$, band 5,6,7, 8a, 11 dan 12 mempunyai ketelitian spasial $20 \mathrm{~m}$ dan band 2,3,4 dan 8 dengan ketelitian spasial $10 \mathrm{~m}$ (Esa, 2013).
Citra sentinel-2 banyak digunakan untuk identifikasi dan analisis perubahan tutupan lahan, pemetaan resiko bencana, perencanaan perkotaan, permasalahan lingkungan dan beragam aplikasi lainnya (Clerici, Valbuena Calderón \& Posada, 2017; Tavares et al., 2019; Lopes et al., 2020). Sentinel-2A merupakan sebuah misi yang dikembangkan dalam program Copernicus Eropa untuk pemantauan lingkungan dan dikembangkan dengan resolusi tinggi (Rosina dan Kopecká, 2016). Penggunaan Sentinel dapat digunakan untuk identifikasi lahan pertanian (Zhang et al., 2017), pemetaan dan deteksi tumpahan minyak (Kolokoussis dan Karathanassi, 2018). Citra Sentinel-2A dapat digunakan untuk evaluasi tingkat keparahan kebakaran dengan baik sehingga dapat digunakan untuk meningkatkan kebijakan manajemen kebakaran. Akurasi yang sangat baik juga menggambarkan kemampuan citra Sentinel-2, baik dari segi spectral maupun spasial untuk mendeteksi daerah perkotaan (Lefebvre et al., 2016).

\section{METODOLOGI}

\section{A. Lokasi Penelitian}

Penelitian ini mengambil wilayah studi Kalimantan Timur dimana pengerjaan data akan dilakukan di Laboratorium Indraja dan SIG, Prodi Teknologi Geomatika, Politeknik Pertanian Negeri Samarinda pada gambar 1 ..

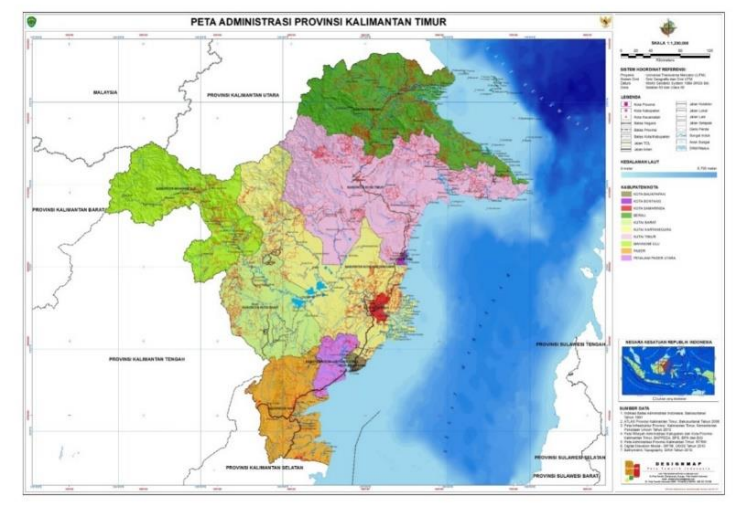

Gambar 1. Peta Administrasi Provinsi Kalimantan Timur

\section{B. Alat dan Bahan}

Dalam kegiatan penelitian ini terdapat beberapa alat dan bahan yang dibutuhkan, yaitu:

1. GPS Geodetik RTK

2. Drone DJI Phantom 4 Advanced

3. GPS Handheld

4. Kayu Ulin

5. Terpal

6. Peta Administrasi Kalimantan Timur

7. Citra Satelit Sentinel-2 Kalimantan Timur

\section{Pelaksanaan Penelitian}

1. Identifikasi Awal Identifikasi awal telah dilakukan sejak tahun 2019 dan 2020 dimana dalam kegiatan FGD (Forum Group Discussion) yang dilakukan oleh dinas 
perkebunan di Balikpapan dipaparkan bahwa kebutuhan data yang valid atas stok karbon yang ada di Provinsi Kaltim sangat dibutuhkan sebagai dasar dalam mengajukan klaim dana dalam program FCPF (Forest Carbon Partnership Facility) - Carbon Fund sementara kondisi ketersediaan data tersebut belum dimiliki oleh setiap kota dan kabupaten di Kalimantan Timur. Untuk itu perlu dilakukan estimasi stok karbon dengan berbagai pendekatan dan dalam hal ini adalah dengan metode penginderaan jauh.

2. Pengumpulan Data

Data yang dikumpulkan terdiri dari data primer dan sekunder. Data primer yang digunakan adalah data ground truth dari tutupan lahan di Kalimantan Timur sejumlah 30 titik yang akan diambil. Sedangkan data sekunder yang digunakan adalah data citra satelit sentinel-2 Provinsi Kalimantan Timur tahun 2021 dan data peta administrasi Provinsi Kalimantan Timur telah diperoleh. Data yang belum diperoleh adalah data ground truth untuk memastikan hasil klasifikasi tutupan lahan sesuai dengan kondisi dilapangan.

3. Pengolahan Data

Data citra sentinel-2 dilakukan koreksi atmosfer untuk menghilangkan pengaruh atmosfer terhadap kualitas data citra satelit. Data yang telah terkoreksi atmosfer kemudian dilakukan komposit citra untuk menampilkan visual citra agar sesuai dengan kenampakan yang sebenarnya sehingga mudah dilakukan identifikasi. Dari hasil komposit citra tersebut kemudian dilakukan klasifikasi untuk memperoleh kelas tutupan lahan yang ada di Provinsi Kalimantan Timur. Hasil klasifikasi tutupan lahan dioverlay dengan data peta administrasi dan selanjutnya dibuat layout untuk memperoleh hasil berupa peta tutupan lahan yang lebih informatif.

4. Perhitungan Karbon dan Emisi Karbon

Perhitungan karbon dan emisi karbon dilakukan dengan menghitung luasan setiap kelas tutupan lahan terlebih dahulu. Dari luasan yang diperoleh kemudian dikalikan dengan factor pengali kandungan karbon sebagaimana ada pada tabel 1 yang selanjutnya dikalikan Kembali dengan factor pengali untuk menghitung emisi karbon yakni 3,67 . Hasil perhitungan berupa nilai estimasi stok karbon dan emisi karbon yang ada di Provinsi Kalimantan Timur.

5. Analisis

Analisis dilakukan dengan membandingkan kelas tutupan lahan hasil pengolahan citra satelit dengan hasil pengamatan ground truth yang. Analisis juga dilakukan terhadap potensi stok karbon dan emisi karbon berdasarkan batas wilayah administrasi Provinsi Kalimantan Timur. Nilai stok karbon dan emisi karbon merupakan nilai estimasi yang diperoleh dengan menggunakan metode penginderaan jauh dan memanfaatkan citra satelit sentinel-2. Dengan data tersebut dapat dianalisis tindakan - tindakan atau kebijakan dalam pengelolaan untuk menjaga stok karbon yang ada disetiap wilayah masing-masing.

6. Pelaporan

Pelaporan dilakukan dengan membukukan kegiatan penelitian secara menyeluruh dalam sebuah laporan akhir.

\section{HASIL DAN PEMBAHASAN}

Pemanfaatan GEE dalam memetakan tutupan lahan dan perhitungan potensi karbon di Provinsi Kalimantan Timur menghasilkan 3 kelas klasifikasi yaitu badan air, pemukiman dan vegetasi sebagaimana dalam tabel 2 .

Tabel 2. Penggunaan Lahan Kalimantan Timur

\begin{tabular}{|c|l|r|}
\hline No & \multicolumn{1}{|c|}{ Kelas } & \multicolumn{1}{c|}{ Luas (ha) } \\
\hline 1 & Badan Air & $384.754,752$ \\
\hline 2 & Pemukiman & $463.396,001$ \\
\hline 3 & Vegetasi & $11.873 .800,520$ \\
\hline \multicolumn{2}{|c|}{ Total (ha) } & $12.721 .951,270$ \\
\hline
\end{tabular}

Dari hasil tersebut dapat dilihat bahwa penggunaan lahan di Provinsi Kalimantan Timur didominasi oleh tutupan vegetasi yang mencapai luasan 11.873.800,520 ha. Secara grafik, luasan penggunaan lahan dapat ditampilkan pada gambar 2 .

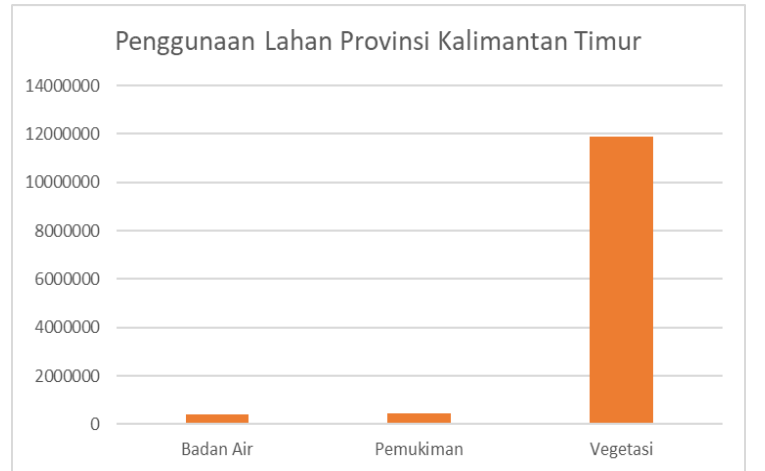

Gambar 2. Diagram Luasan Penggunaan Lahan Provinsi Kalimantan Timur.

Tutupan dan luasan yang diperoleh tersebut merupakan hasil dari script pada GEE. Tutupan lahan hasil pengolahan dengan GEE dapat dilihat pada gambar 3.

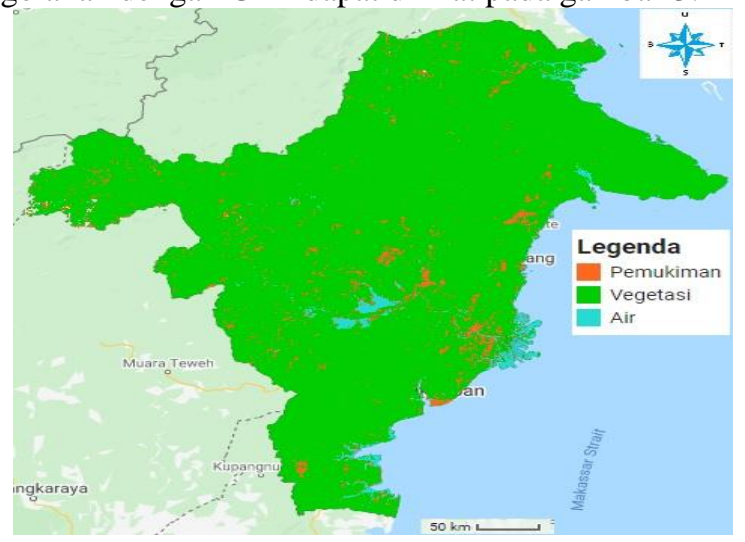

Gambar 3. Tutupan Lahan Provinsi Kalimantan Timur 
Dari hasil tutupan lahan tersebut dapat diperoleh nilai potensi karbon di Provinsi Kalimantan Timur sebagaimana terdapat pada tabel 3.

\begin{tabular}{|c|c|c|}
\hline No & Penggunaan & $\begin{array}{c}\text { Nilai Karbon } \\
\text { (ton) }\end{array}$ \\
\hline 1 & Badan Air & 0 \\
\hline 2 & Pemukiman & $3.243 .772,01$ \\
\hline 3 & Vegetasi & $758.023 .425,14$ \\
\hline \multicolumn{2}{|r|}{ Total } & $761.267 .197,15$ \\
\hline
\end{tabular}

Dari tabel diatas terlihat bahwa Provinsi Kalimantan Timur memiliki potensi karbon sebesar 761.267.197.15 ton. Potensi ini merupakan potensi dari 2 kelas hasil klasifikasi citra satelit sentinel-2 yakni pemukiman dan vegetasi yang dikalikan dengan rata-rata dari kelas kandungan karbon tiap kelas vegetasi dan pemukiman pada tabel 1. Potensi sebesar ini merupakan potensi luar biasa yang akan mampu mempengaruhi kondisi lingkungan di dunia.

\section{KESIMPULAN}

Hasil pengolahan citra sentinel-2 menunjukkan bahwa Provinsi Kalimantan Timur memiliki luasan wilayah sebesar 12.721.951,270 ha dengan potensi karbon sebesar 761.267.197,15 ton. Nilai potensi ini merupakan potensi luar biasa yang akan mampu mempengaruhi kondisi lingkungan di dunia.

\section{UCAPAN TERIMA KASIH}

Terima kasih diucapkan ke Politeknik Pertanian Negeri Samarinda yang telah membantu pendanaan penelitian ini.

\section{DAFTAR PUSTAKA}

Bakri. 2009. Analisis Vegetasi Dan Pendugaan Cadangan Karbon Tersimpan Pada Pohon Di Hutan Taman Wisata Alam Taman Eden Desa Sionggang Utara Kecamatan Lumban Julu Kabupaten Toba Samosir. Medan: Universitas Sumatera Utara.

Clerici, N., Valbuena Calderón, C. A. and Posada, J. M. 2017. Fusion of sentinella and sentinel-2A data for land cover mapping: A case study in the lower Magdalena region, Colombia. Journal of Maps. doi: 10.1080/17445647.2017.1372316.

Daud, M. H. Latifah, H. Basalamah dan Sarman. 2014. Potensi Biomassa, Cadangan Karbon dan Serapan Karbon Dioksida Pada Kebun Raya Massenrempulu Enrekang. Jurnal Matoa. 002 (3): 54-63. (ISSN:2337- 9200).

Departemen Kehutanan dan Perkebunan. 1999. Undangundang Nomor 41 Tahun 1999 tentang Kehutanan. Dephutbun RI. Jakarta.

Esa (2013). User Handbook Issue 1 Revision 1 SENTINEL-2.
EUROSTAT. 2001. Manual of concepts on land cover and land use information systems. Available at: http://europa.eu.int. Dikunjungi pada tanggal 4 Mei 2021, Pukul 16.30 WITA.

Fariz, H., Atmawidjaja, R. dan Krsnawati, D. 2014. Identifikasi Penutup Lahan Menggunakan Citra Satelit SPOT 4. Institut Pertanian Bogor. Bogor.

Hairiah K, Rahayu S. 2007. Pengukuran Karbon Tersimpan di Berbagai Penggunaan Lahan. Bogor: World Agroforestry Centre \pm (ICRAF SEA) Regional Office, University of Brawijaya, Indonesia.

Kolokoussis P, Karathanassi V. 2018. Oil Spill Detection and Mapping Using Sentinel 2 Imagery Journal of Marine Science and Engineering. 6(1): 4.

Lefebvre A, Sannier C, Corpetti T. 2016. Monitoring urban areas with Sentinel-2A data: Application to the update of the Copernicus high resolution layer imperviousness degree Remote Sensing. 8(7): 606.

Lopes, M. et al. 2020. Combining optical and radar satellite image time series to map natural vegetation: savannas as an example. Remote Sensing in Ecology and Conservation. WileyBlackwell. doi: 10.1002/rse2.139.

Rahman, M. 1992. Jenis dan Kerapatan Pohon Dipterocarpacea di Bukit Gajabuih Padang. Jurnal Matematika dan Pengetahuan Alam.Vol. 2. No. 1.

Rosina K, Kopecká M. 2016. Mapping of urban green spaces using sentinel-2A data: methodical aspects. 6th International Conference on Cartography and GIS, Albena. Bulgarian Cartographic Association (in print). 562-568.

SNI-7724-2011. Pengukuran dan Perhitungan Cadangan Karbon. Badan Standarisasi Nasional.

Sularso, M.N.G. Hermawan, R. dan Prasetyo, B. L. 2011. Pendugaan Perubahan Cadangan Karbon di Taman Nasional. Semiloka Nasional: Implementasi RAN-GRK untuk Bidang Berbasis Lahan, Botani Square- IPB, Bogor.

Lusiana B, van Noordwijk M, Rahayu S. 2005. Carbon Stocks in Nunukan, East Kalimantan: A Spatial Monitoring and Modelling Approach. Report from the carbon monitoring team of the Forest Resources Management for Carbon Sequestration (FORMACS) project. Bogor: World Agroforestry Centre - ICRAF, SEA Regional Office.

Tavares, P. A. et al. 2019. Integration of sentinel-1 and sentinel-2 for classification and LULC mapping in the urban area of Belém, eastern Brazilian Amazon. MDPI AG, 19(5). doi: 10.3390/s19051140.

Tosiani, A. 2015. Buku Kegiatan Serapan dan Emisi Karbon. Kementerian Lingkungan Hidup dan Kehutanan, Direktorat Jenderal Planologi Kehutanan dan Tata Lingkungan, Direktorat Inventarisasi dan Pemantauan Sumberdaya Hutan. Jakarta. 
Whitmore, T. C. (1995). The Phytogeography of Malesian Euphorbiaceae. In: Plant Diversity in Malesia III. Proceedings of the Third International Flora Malesiana Symposium 1995. J Dransfield, MJE Coode \& DA Simpson (eds.). Royal Botanic Gardens Kew. Pp. 389-390
Zhang T, Su J, Liu C, Chen WH, Liu H, Liu G. 2017. Band selection in sentinel-2 satellite for agriculture applications. Automation and Computing (ICAC), 2017 23rd International Conference on, IEEE. 